\title{
The Vertical Proximally Based Turn Over Gingivolabial Myomucosal Flap for Closure of Anterior Palatal Fistula
}

\author{
RAAFAT ABD-ALLATIF ANANI, M.D.; MAHFOUZ SHEHATA IBRAHIM AHMED, M.D., M.R.C.S. and \\ EMAD SALAH IBRAHIM, M.D.
}

The Department of Plastic Surgery, Faculty of Medicine, Zagazig University, Zagazig, Egypt

\begin{abstract}
Background: Palatal fistula is the most common complication following cleft palate repair. Plenty of reconstructive procedures have been described for repair of these fistulas. This study describes a reliable technique of vertical proximally based turn over gingivolabial myomucosal flap for closure of anterior palatal fistulas.

Methods: Thirty four patients presented with large sizes anterior palatal fistulas underwent closure using vertical proximally based turn over gingivolabial myomucosal flaps. The procedure is a single stage with nasal layer closure while oral layer left for re epithelialization.

Results: All flaps completely survived. Two out of 34 flaps $(5.8 \%)$ suffered distal necrosis which improved after debridement and secondary suturing but no other complications. All fistulas were completely healed without any evidence of recurrence during a mean follow-up period of 18 months.

Conclusion: The vertical proximally based turn over gingivolabial myomucosal flap is a simple single stage technique. The flap is a reliable good option for closure of anterior fistula in presenting age groups without donor site morbidity. It is suited for most anterior located palatal fistulas and medium sized ones.
\end{abstract}

Key Words: Vertical - Turn over - Gingivolabial - Flap Anterior - Palatal - Fistula.

\section{INTRODUCTION}

Palatal fistula is the most common complication of cleft palate surgery with a reported incidence between four and 58\% [1-3]. The most common reported cause is tension at suture line [4]. The common sites are anterior portion of hard palate and the junction between the hard and soft palate [5].

Wide size fistula is leading not only to escape of fluid and food into the nasal cavity but also to nasal tone due to escape of air during speech [6].

The currently available techniques for fistula repair are mucoperiosteal flaps, tongue flaps, skin flaps, buccal fat pads, a cellular dermal matrices, lip myomucosal flaps, buccinators musculomucosal flaps and free tissues [7-13].

Jensen et al., 2010 denotes that gingival, labial, buccal and palatal vessels are richly anastomosed with periodental plexus and hence the bases for this study [14].

The aim of this study is evaluation of usefulness of vertical proximally based turn over gingivolabial myomucosal flap in closure of anterior palatal fistulas.

\section{PATIENTS AND METHODS}

Between December 2015 and January 2019 (37 months) in Plastic Surgery Department, Zagazig University a total of 34 children's were presented with anterior palatal fistulas post repair of cleft palates. In this study the most anterior located palatal fistulae (just behind the alveolar margins) were chosen for the study as the flaps has limited lengths. Twenty patients were operated for first time for residual anterior fistulas after cleft palate repair while 14 patients were operated two times or more. All fistulas were large sizes (more than $5 \mathrm{~mm}$ according to classification done by Cohen et al., 1991) [15]. The mean defect size was $10.3 \mathrm{~mm}$ (ranged from $5 \mathrm{~mm}$ to $20 \mathrm{~mm}$ ). Twelve of them had also repaired cleft lip as well but no other congenital anomalies. Eighteen were males and sixteen were females. The mean age was five years with range between three and nine years and ages more than this were excluded. The elected procedure was approved from the university review committee. Written informed consents were taken from all parents. Patient's demographic flaps characters were illustrated in Table (1). 


\section{Operative technique:}

Under general anesthesia with oral endotracheal intubation, a dingman mouth gag was used to adequately expose the affected area. A single dose of prophylactic antibiotic cefazolin (25 milligram per each kilogram) was given at time of induction. Measurement of the defect size was first done. Marking of the flap at inner surface of the upper lip was designed just opposite to the defect. It is vertical in all except three patients where distal end of the flap was slightly angled to increase its length and to fit to defect shape Fig. $(1 \mathrm{~A}, \mathrm{~B})$ and Fig. $(2 \mathrm{~A}, \mathrm{~B})$.

The mucoperiosteum was elevated from the edges of the fistula which could not close the nasal side because of fistula size and or tissue fibrosis. The myomucosal flap was then elevated starting distally just proximal to the red margin then proceeded proximally where a part of the orbicularis muscle included at the flap undersurface in the aim of achieving good vascularity. The flap base to width ratio is either one to two or one to three to avoid vascular compromise. The proximal part of the flap as well as the way till the fistula defect was deepithelialized. The flap was turned upside down between the incisor teeth which were spaced in this age group. Fig. (1C,D) and Fig. (2C). The area between two teeth is then deprived from its epithelium. This will help the deepithelialized part of the flap to adhere to this area (that's why it is a single stage repair). The mucosa of the flap was then sutured to the elevated mucoperiosteum making the nasal layer. The muscle surface was sutured to the surrounding tissues (oral mucosa). The oral surface was left to reepithelialize from the adjacent oral mucoperiosteum. The donor site was closed in two layers with muscle layer first then the mucosa.

The patients given oral feeding same day with only cups neither straws nor spoons were allowed for two weeks. The children's were kept for 48 hours in the hospital till the flap viability was ascertained.

\section{RESULTS}

All fistulae were an anterior of large sizes. Nasal sides were closed completely at time of operations. All oral side wounds achieved healing by reepithelialization within two to three weeks. Follow-up in outpatient clinic done at regular intervals of one week, one month then afterwards every two months.
During post-operative evaluation only two flaps (5.8\%) suffered distal necrosis but after debridement and secondary sutures they did well. During early week's post-operatively mild gingival thickening were seen but became not noticeable after two to three months as the muscular part atrophies. We achieved complete sealing of all fistulas. There were no evidence of recurrences, wound dehiscence, nor wound infections within a mean followup of 18 months (ranged between five and 32 months). In all cases the flaps passed between the incisor teeth and the mucosa in between was ablated so the flaps under surfaces adhere to it and no need for secondary stages. Donor sites were healed without any complications. We noticed difficulty of feeding within first two days but as parents were learned how to feed their children's, they become compatible thereafter Fig. (1E), Fig. (2D), (Table 1).

Table (1): Patient's demographics, anterior palatal fistula characters and complications.

\begin{tabular}{|c|c|c|c|c|c|}
\hline Number & Age & Sex & $\begin{array}{c}\text { Type of } \\
\text { operation }\end{array}$ & $\begin{array}{c}\text { Defect } \\
\text { size mm }\end{array}$ & Complications \\
\hline 1 & 3 & Male & First & 8 & No \\
\hline 2 & 6 & Female & First & 7 & No \\
\hline 3 & 8 & Male & Third & 14 & No \\
\hline 4 & 5 & Female & Second & 9 & No \\
\hline 5 & 6 & Female & First & 7 & No \\
\hline 6 & 5 & Female & Second & 10 & Distal flap necrosis \\
\hline 7 & 4 & Male & First & 6 & No \\
\hline 8 & 4 & Female & First & 9 & No \\
\hline 9 & 3 & Male & First & 8 & No \\
\hline 10 & 6 & Female & Second & 7 & No \\
\hline 11 & 5 & Female & First & 8 & No \\
\hline 12 & 3 & Female & First & 9 & No \\
\hline 13 & 4 & Male & Second & 20 & No \\
\hline 14 & 6 & Female & First & 7 & No \\
\hline 15 & 9 & Female & Third & 9 & No \\
\hline 16 & 4 & Female & First & 8 & No \\
\hline 17 & 9 & Male & Third & 20 & No \\
\hline 18 & 5 & Female & First & 8 & No \\
\hline 19 & 4 & Male & First & 8 & No \\
\hline 20 & 6 & Male & Second & 15 & No \\
\hline 21 & 8 & Male & Third & 16 & Distal flap necrosis \\
\hline 22 & 5 & Female & First & 7 & No \\
\hline 23 & 3 & Male & First & 5 & No \\
\hline 24 & 6 & Male & Second & 18 & No \\
\hline 25 & 5 & Female & First & 7 & No \\
\hline 26 & 4 & Male & First & 10 & No \\
\hline 27 & 4 & Female & First & 8 & No \\
\hline 28 & 6 & Male & Third & 14 & No \\
\hline 29 & 5 & Male & Second & 12 & No \\
\hline 30 & 4 & Male & First & 6 & No \\
\hline 31 & 3 & Male & First & 8 & No \\
\hline 32 & 7 & Female & Third & 17 & No \\
\hline 33 & 5 & Male & Second & 20 & No \\
\hline 34 & 3 & Male & First & 7 & No \\
\hline
\end{tabular}

First operation means that only done cleft palate repair and complicated by anterior palatal fistula and this is the first attempt, while two or more operations mean that more than one or more failed previous attempts at fistulas repair were done. Defect size represented by its widest dimension. 


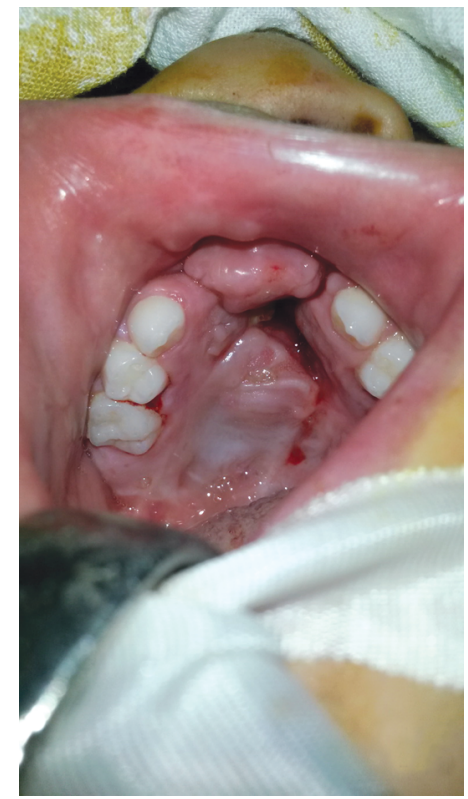

Fig. (1A): Pre-operative 4 years child with anterior palatal fistula measuring $2 \mathrm{~cm} \mathrm{X} 1 \mathrm{~cm}$ at its widest dimensions with premaxilla cleft which was operated two times before.

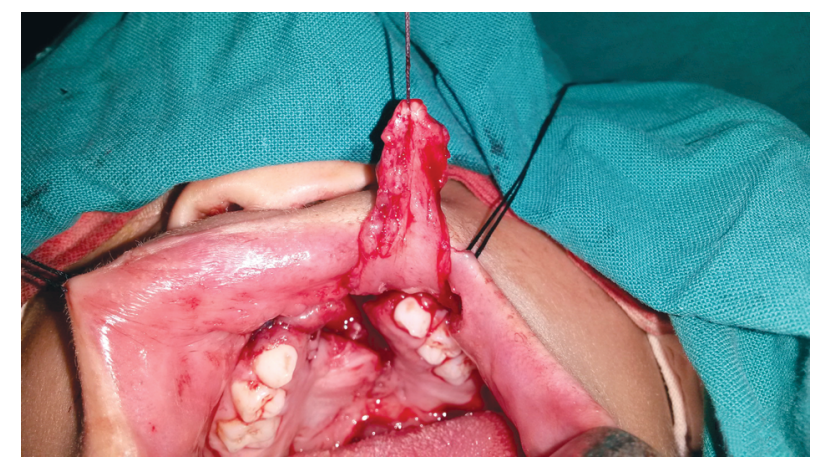

Fig. (1C): Elevated flap.

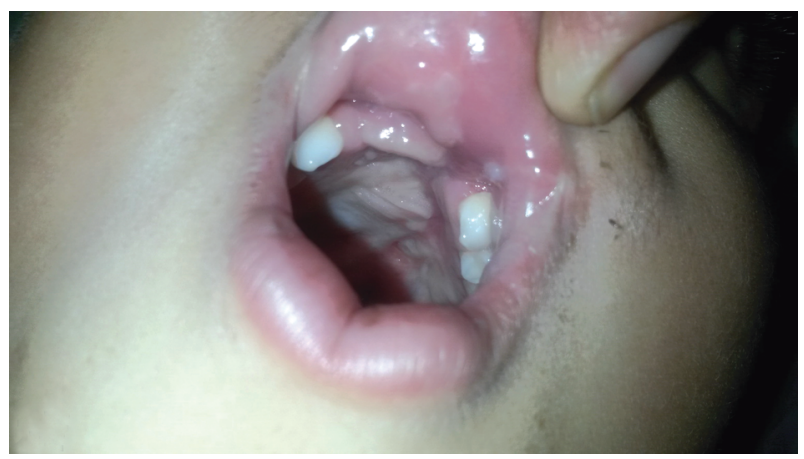

Fig. (1E): Six months post-operatively, complete closure of the fistula achieved using vertical proximally based turn over gingivolabial myomucosal flap with premaxillary defect also closed after paring of its epithelium. Donor site shows no any morbidity.

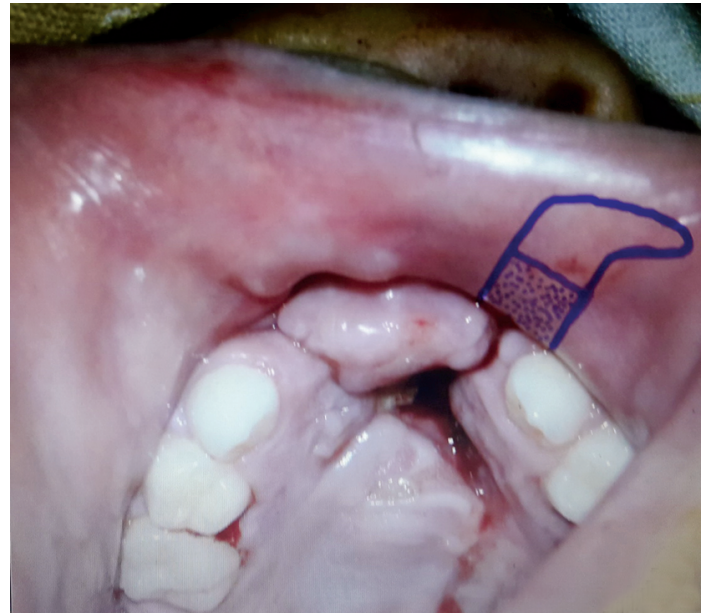

Fig. (1B): Flap design and the part to be depithelialized is marked by dots.

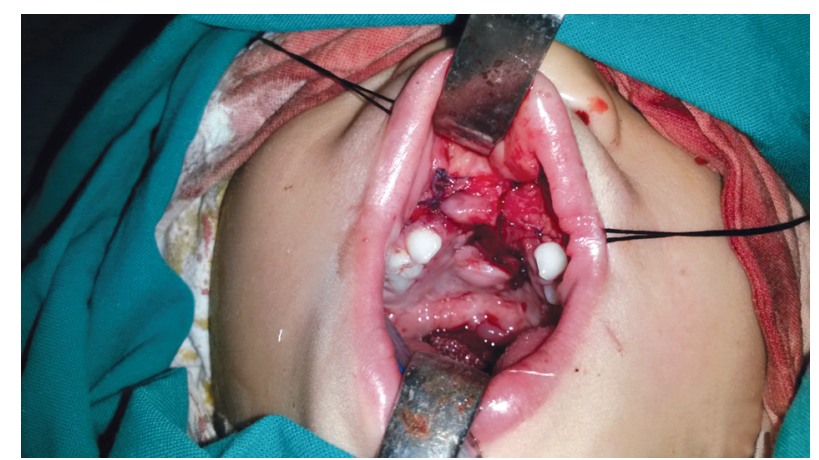

Fig. (1D): An intraoperative photo shows depithelialized gingivolabial turn over flap inset.

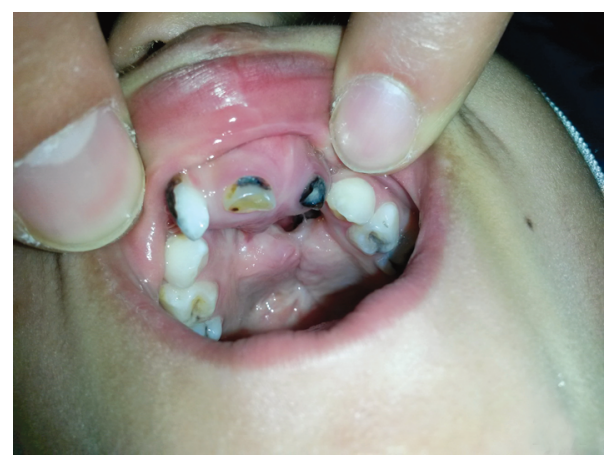

Fig. (2A): A child 6 years presented with anterior palatal fistula operated one time. Defect size is about $1.5 \mathrm{~cm} \mathrm{X} 1 \mathrm{~cm}$. 


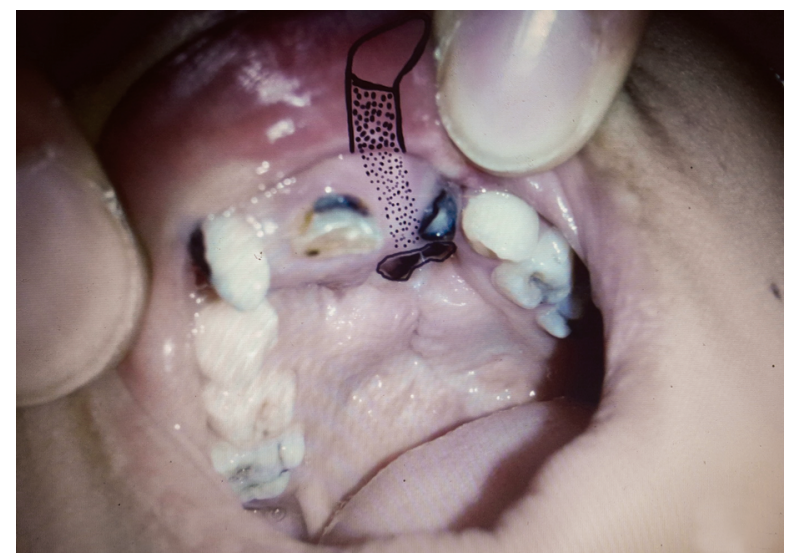

Fig. (2B): Marking of the vertical proximally based turn over gingivolabial myomucosal flap about $20 \%$ more than defect size with slight inclination to increase flap length and dotted area point to the deepithelialized part.

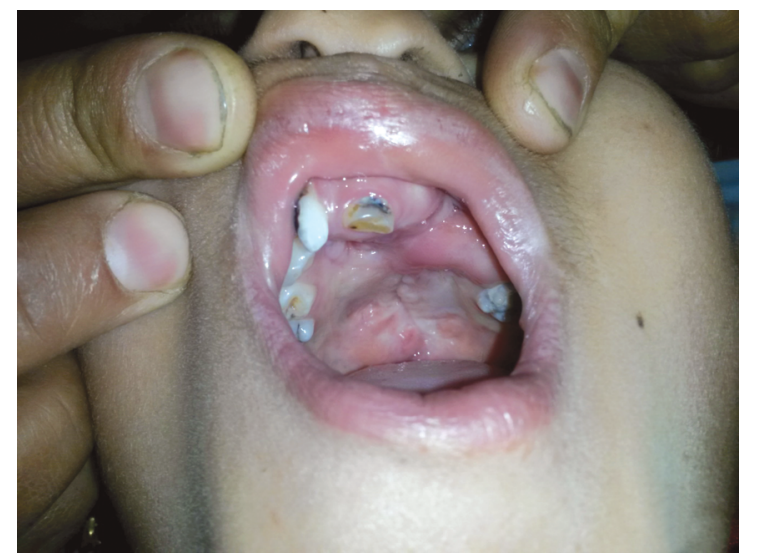

Fig. (2D): Seven months post-operative of six years old child with complete fistula closure without any donor site morbidity.

\section{DISCUSSION}

Palatal fistula is the most common complication of cleft palate repair with reported incidence ranged from four to 58\% [1-3]. Tissues around the fistula are usually stiff, fibrotic and difficult to mobilize [16]. Fistula repair has high rate of recurrence which ranged from 33 to $37 \%$ [15,17,18].

Several procedures have been performed to repair palatal fistula $[\mathbf{1 5 , 1 8 , 1 9 ]}$. Mucoperiosteal flaps although can be used for repair but it can be difficult if the fistula size is large and more anterior placement [20]. Tongue flaps are good options for large anterior fistulas but its drawbacks are two stage procedures, risk of flaps breakdown, difficulty of intubation during flap division and it interfere with speech and eating [21].

The posterior based buccinator myomucosal flap is a good option with reliable blood supply but it only used for posterior fistula and unreliable

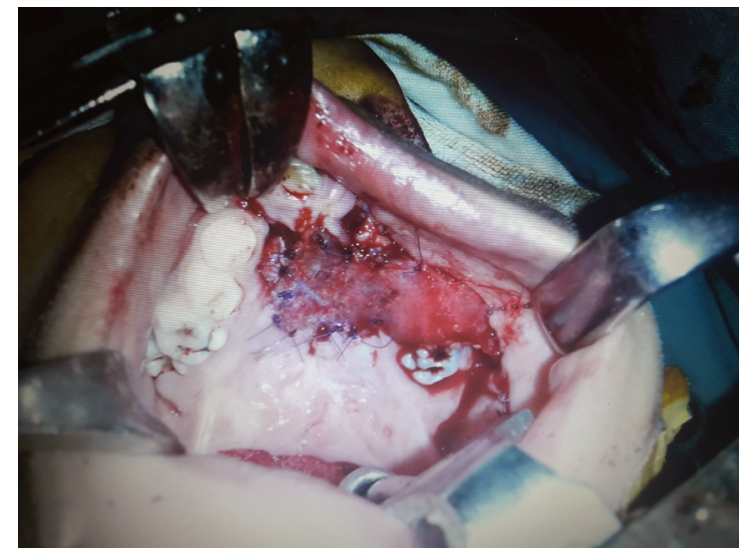

Fig. (2C): An intraoperative photo showing suturing of deepithelialized turned upside down gingivolabial flap and donor site closure.

for anterior one and if used for anterior one it requires a procedure to maintain open bite [22-24]. Anterior based mucosal and or myomucosal flaps were tried for anterior fistula but the angle of rotation sometimes causes flaps loss and also two stages [12].

Upper lip myomucosal flap was tried by Elsherbiny et al., but their procedure was two staged and also their technique had $30 \%$ recurrence rate [25].

This study evaluated the use of the vertical proximally based turn over gingivolabial myomucosal flap for closure of anterior palatal fistula. The flap has rich blood supply due to the rich anastomisis between labial, buccal, gingival, palatal and periodontal plexuses [14].

The flap harvest technique is a simple one. The flap is turned upside down up on itself and as its blood supply comes from its back so no affection of its vascularity. Donor site was closed primary without any morbidity. The flap is a single stage so only one hospitalization. The results proved high success rate in closure of anterior fistula without any recurrence or interference with eating or speech during the long follow-up period.

The limitations of this technique are it is only applicable for anterior located palatal fistulas in ages with deciduous teeth and it is not suitable for very large sized fistulas because of difficulty of donor site closure.

\section{Conclusion:}

The vertical proximally based turn over gingivolabial myomucosal flap is a simple, single stage technique. The flap is a reliable good option for 
closure of anterior palatal fistula without donor site morbidity. The only limitations are size (no more than $2 \mathrm{~cm}$ ), age (we chose ages between 3 and 9 years) and site of fistula (good results are achieved with most anterior located fistula).

\section{Conflicts of interest:}

None declared

\section{Funding:}

None

\section{REFERENCES}

1- Sadove A.M. and Eppley B.L.: Cleft lip and palate, in: Grosfeld J.L., O'Neill J.A., Coran A.G., Fonkalsrud E.W., Caldamone A.A. (Eds.), Pediatric Surgery, $6^{\text {th }}$ ed., Mosby Elsevier, Philadelphia, 803-12, 2006.

2- Landheer J., Breugm C. and Molin M.V.: "Fistula incidence and predictors of fistula occurrence after cleft palate repair: Two-stage closure versus one-stage closure. The Cleft Palate Craniofac. J., 47: 623-30, 2010.

3- Fang L., Yang M., Wang C., Ma T., Zhao Z., Yin N., Wei L. and Yin J.: A clinical study of various buccinator musculomucosal flaps for palatal fistulae closure after cleft palate surgery. J. Craniofac. Surg., 25: 197-202, 2014.

4- Li H., Yin N. and Song T.: Oronasal fistula repair using the alveolar ridge approach. Int. J. Pediatr. Otorhinolaryngol., 79: 161-4, 2015.

5- Smith D.M., Vecchione L., Jiang S., Ford M., Deleyiannis F.W. and Haralam M.A.: The pittsburgh fistula classification system: A standardized scheme for the description of palatal fistulas. Cleft Palate Craniofac. J., 44: 590-4, 2007.

6- Inman D.S., Thomas P., Hodgkinson P.D. and Reid C.A.: Oro-nasal fistula development and velopharyngeal insufficiency following primary cleft palate surgery-an audit of 148 children born between 1985 and 1997. Br. J. Plast. Surg., 58: 1051-4, 2005.

7- Perko M.A.: Primary closure of the cleft palate using a palatal mucosal flap: An attempt to prevent growth impairment. J. Maxillofac. Surg., 2: 40-3, 1974.

8- Guzel M.Z. and Altintas F.: Repair of large, anterior palatal fistulas using thin tongue flaps: Long-term follow-up of 10 patients. Ann. Plast. Surg., 45: 109-14, 2000.

9- Batchelor A.G. and Palmer J.H.: A novel method of closing a palatal fistula: The free fascial flap. Br. J. Plast. Surg., 43: 359-61, 1990.

10- Ashtiani A.K., Fatemi M.J., Pooli A.H. and Habibi M.: Closure of palatal fistula with buccal fat pad flap. Int. J. Oral Maxillofac. Surg., 40: 250-4, 2011.

11- Steele M.H. and Seagle M.B.: Palatal fistula repair using acellular dermal matrix: The University of Florida experience. Ann. Plast. Surg., 56: 50-3, 2006.
12- Abdel-Aziz M., Abdel-Nasser W., El-Hoshy H., Hisham A. and Khalifa B.: Closure of anterior post-palatoplasty fistula using superior lip myomucosal flap. Int. J. Pediatr. Otorhinolaryngol., 72: 571-4, 2008.

13- Rahpeyma A. and Khajehahmadi S.: Closure of Huge Palatal Fistula in an Adult Patient with Isolated Cleft Palate: A Technical Note. Plast. Reconstr. Surg. Glob. Open, 3: 306-8, 2015.

14- Jensen O.T., Bello W. and Cottam J.: Osteoperiosteal flaps and local osteotomies for alveolar reconstruction in Waite PD (Editor). Alveolar bone grafting techniques for dental implant preparation, $1^{\text {st }}$ ed, Saunders, USA. 331-46, 2010.

15- Cohen S.R., Kalinowski J., La Rossa D. and Randall P.: Cleft palate fistulas: A multivariate statistical analysis of a prevalence, etiology and surgical management. Plast. Reconstr. Surg., 87: 1041-7, 1991.

16- Honnebier M.B., Johnson D.S., Parsa A.A., Dorian A. and Parsa F.D.: Closure of palatal fistula with a local mucoperiosteal flap lined with buccal mucosal graft, Cleft Palate Craniofac. J., 37: 127-9, 2000.

17- Amaratunga N.A.: Occurrence of oronasal fistulas in operated cleft palate patients. J. Oral Maxillofac. Surg., 46: 834, 1988.

18- Muzzafar A.R., Byrd H.S., Rohrich R.J., Johns D.F., Le Blanc D., Beran S.J. and Anderson C.: Incidence of cleft palate fistula: An institutional experience with two-stage palatal repair. Plast. Reconst. Surg., 108: 1515, 2001.

19- Eberlinc A. and KoČelj V.: Incidence of residual oronasal fistulas: A 20-year experience. Cleft Palate Craniofac. J., 49: 643-8, 2012.

20- Freda N., Rauso R., Curinga G., Clemente M. and Gherardini G.: Easy closure of anterior palatal fistula with local flaps. J. Craniofac. Surg., 21: 229-32, 2010.

21- Strujak G., Carvalho T., Biron C., Soares A.A. and Carlini L.: Pedicle Tongue Flap for Palatal Fistula Closure. J. Craniofac. Surg., 27: 2146-8, 2016.

22- Kobayashi S., Fukawa T., Hirakawa T. and Maegawa J.: The Folded Buccal Musculomucosal Flap for Large Palatal Fistulae in Cleft Palate. Plast. Reconstr. Surg. Glob. Open, 112: 1-4, 2014.

23- Sohail M., Bashir M.M., Khan F.A.z. and Ashraf N.: Comparison of Clinical Outcome of Facial Artery Myomucosal Flap and Tongue Flap for Closure of Large Anterior Palatal Fistulas. J. Craniofac. Surg., 27: 14658, 2016.

24- Sarabahi S. and Tiwari V.K.: Orbicularis oris musculomucosal flap for anterior palatal fistula. Indian J. Plast. Surg., 39: 148-51, 2006.

25- Elsherbiny M., Saed B., Sheir H., Elzohiri M., Asharf T., Elshafey A. and El-Ghazaly M.: Upper lip myomucosal flap for the repair of anterior oronasal fistula. Annal. Pedia. Surg., 14: 171-3, 2018. 